\title{
Maternal and Foetal Outcomes Following Intra- Partum Complementary and Alternative Medicine ingestion: A Prospective Cohort Study
}

\author{
Dohbit JS ${ }^{1,2}$, Meka ENU ${ }^{1,2}$, Noa NC ${ }^{2,3}$, Essiben $\mathrm{F}^{2,4}$, Nguedje $\mathrm{ML}^{2}$, Joel Noutakdie Tochie ${ }^{5 *}$, Ofakem $\mathrm{II}^{2}$, Valirie Ndip \\ Agbor ${ }^{6,7}$, Jan Rene Nkeck $^{8}$, Mbia $\mathbf{K Z}^{2}$ and Foumane $\mathbf{P}^{1,2}$ \\ ${ }^{1}$ Departement of Gynaecology and Obstetrics, Yaoundé Gynaeco-Obstetrics and Paediatric Hospital, Cameroon \\ ${ }^{2}$ Departement of Gynaecology and Obstetrics, University of Yaoundé, Cameroon
}

${ }^{3}$ Paul and Chantal Biya Hospital Centre for endoscopic surgery and human reproduction, Cameroon

${ }^{4}$ Departement of Gynaecology and Obstetrics, Yaoundé Central Hospital, Cameroon

${ }^{5}$ Departement of Surgery and Specialities, University of Yaoundé, Cameroon

${ }^{6}$ Ibal Sub divisional Hospital, Oku, North West Region

${ }^{7}$ Department of Clinical Research, Health Education and Research Organisation (HERO), Cameroon

${ }^{8}$ Departement of Internal Medicine, University of Yaoundé, Cameroon

Submission: August 20, 2018; Published: November 02, 2018

*Corresponding author: Joel Noutakdie Tochie, Faculty of Medicine and Biomedical Sciences, University of Yaounde, Joseph Tchooungui Akoa, Yaounde, Cameroon,

Abstract

Introduction: Worldwide, 20 to $60 \%$ of pregnant women use Complementary and Alternative Medicine (CAM) during pregnancy. In Cameroon, the prevalence is estimated at $31.5 \%$. The main perceived reasons for pregnant women using it include treatment of nausea and vomiting as well as to ease childbirth. Although widely used in Cameroon, no study in has either demonstrated its safety or effectiveness. The aim of this study was to determine the effects of oral CAM intake during labour on the maternal and foetal outcomes.

Methods: A cohort study was conducted from January to April 2016 in two referral maternity departments of Yaounde, Cameroon. We consecutively enrolled all consenting pregnant women in labour after 28 weeks of gestation. Participants were interviewed using a pretested and coded questionnaire. We divided them into two groups; exposed and unexposed. The exposure studied was ingestion of CAM within 72 hours prior to delivery. Variables studied were socio-demographic characteristics, type and frequency of CAM ingested and details of labour. Logistic regression was performed to identify independent variables for CAM use and materno-foetal complications.

Results: We enrolled a total of 603 paturients of whom 147 in the exposed group and 456 in the non-exposed group. The most frequently used CAM were honey and Triumfettapentandra A. The mean participants age was $28.88 \pm 6.31$ years in the exposed group and $27.90 \pm 6.30$ years in the non-exposed group. Cohabitation $(\mathrm{RR}=1.79,95 \% \mathrm{CI} 1.10-2.94, \mathrm{p}=0.016)$ and tertiary level of education $(\mathrm{RR}=1.5895 \% \mathrm{CI} 1.08-2.33$, $\mathrm{p}=0.012$ ) predisposed to intrapartum CAM ingestion. Women who ingested CAM during labour were more likely to have intra-partum vaginal bleeding $(\mathrm{RR}=1.51,95 \% \mathrm{CI}=1.10-2.08, \mathrm{p}=0.011)$, dystocic labour $(\mathrm{RR}=1.45,95 \% \mathrm{CI}=1.10-1.91, \mathrm{p}=0.007)$, uterine hyper kinesia $(\mathrm{RR}=1.27$, $95 \% \mathrm{CI}=1.06-1.52, \mathrm{p}=0.008)$ and uterineatony $(\mathrm{RR}=7.24,95 \% \mathrm{CI}=1.90-27.63, \mathrm{p}=0.002)$. No correlation was observed between CAM intake and neonatal complications.

Conclusion: Overall, these findings may serve as a preliminary reference to refute CAM use during labour in our resource-constrained environments.

Keywords: Complementary and alternative medicine; Labour; Maternal; Foetal; Outcome

Abbreviations: CAM: Complementary and Alternative Medicine; CI: Confidence Interval; RR: Relative Risks

\section{Introduction}

"Complementary and Alternative Medicine (CAM)" commonly called Traditional medicine in Africa is the sum of all knowledge, skills and practices that are based on the theories, beliefs and experiences of health preservation, specific to different cultures, whether explainable or not, which are used in health preservation, as well as in the prevention, diagnosis, improvement or treatment of physical or mental illness [1]. In CAM, drugs of the traditional 


\section{Global Journal of Reproductive Medicine}

pharmacopoeia, called "herbal medicines" are used. The World Health Organization estimates that $80 \%$ of the general populations, especially women make use of it $[1,2]$. According to a study conducted in 2012 in Cameroon, $31.02 \%$ of women use CAM during the second half of pregnancy [4]. However, its intake during pregnancy is associated with obstetrical, foetal and neonatal complications. A study conducted in South Africa reported that the use of CAM increased the rates of emergency cesarean and foetal distress [5]. Despite the potential adverse maternal and foetal out comes of CAM, studies conducted on the subject in Cameroon are rare. The objective of our study was to identify the effects of ingestion of CAM during the labour on the maternal and foetal outcomes.

\section{Methods}

\section{Study design, setting and participants}

This was a prospective cohort study conducted from January 1 to April 30, 2016, in the maternity wards of two referral hospitals in Cameroon - the Gyneco-obstetrics and Pediatric Hospital of Yaounde and the Central Hospital of Yaounde. An exposed group (consisting of pregnant women who had ingested CAM within 72 hours prior to delivery) was compared to an unexposed group (pregnant women who had not ingested CAM within 72 hours prior to delivery). We excluded all parturients with a gestational age less than 28 weeks, those who did not consent to participate to the study, paturients in whom labour was induced, those with intrauterine fetal death prior to the onset of labour, those with multiple gestations and those who delivered before hospital admission and those undergoing elective cesarean section. The sampling method was exhaustive and consecutive. Assuming a 95\% confidence interval (CI), 31.02\% rate of CAM use [3], the SCHULZ and GRIMES formula was used to obtain a minimum size of our sample of 89 subjects per group. The sampling method was exhaustive and consecutive.

\section{Data collection}

A pre-tested questionnaire was used to collect information on the socio-demographic characteristics (age, level of education, and marital status), CAM details (type of CAM ingested, frequency of intake and amount), labour details (reason for admission, duration of the second period of labour, use of oxytocins, complications during Labour), delivery details (mode of delivery, APGAR score at the 1st and 5th minute, delivery complications such as acute foetal distress and uterine atony).

\section{Data analysis and management}

The data was collected, recorded and analyzed using Epi-info 3.5.4 software. The categorical variables were compared using the Chi-square test and the Fisher exact test when appropriate. The factors associated with CAM use were identified by calculating the risk ratio (RR) with its $95 \%$ confidence interval (CI). The association between CAM use and different variables was measured using the relative risks (RR) and its 95\% confidence interval (CI). Logistic regression was performed for all variables whose $\mathrm{p}$ value was $<0.1$.

\section{Results}

\section{Incidence and reasons for ingestion of traditional medicine during labour}

A total of 603 paturients met our inclusion criteria. One hundred and forty-seven (147) took CAM during labor or in the 72 hours preceding delivery (exposed group) and 456 who did not (the non-exposed group). Hence, the incidence rate of CAM in take during labour was $24.4 \%$. The types of CAM used by parturients are summarized in Table 1. The most frequently used CAM were honey in $28.2 \%$ and Triumfettapentandra A. ("nkui") in $23.7 \%$ of the cases. Several parturients used a combination of TM. The main reasons for the ingestion of CAM were to ease delivery (83.3\%), to induce labour $(21.36 \%)$ or to treat constipation (10\%).

Table 1: Distribution of the list of Complementary and Alternative Medicine used in terms of percentage use; reason for using and subjective perception.

\begin{tabular}{|c|c|c|c|}
\hline Complementary and Alternative Medicine & N (\%) & Most reported reason for its intake & Subjective perception \\
\hline Honey & $41(28.2 \%)$ & Ease labour & Very effective \\
\hline Triumfetta pentandra A. (nkui) & $35(23.7 \%)$ & Ease delivery & Very effective \\
\hline Hibiscus leaves (Hibiscus rosa-sinensis) & $29(20 \%)$ & Ease delivery & Very effective \\
\hline Brimstone tree leaves (Morinda lucida) & $26(17.7 \%)$ & To induce labour & Very effective \\
\hline Lemon grass (Cymbopogon citratus) & $17(11.4 \%)$ & Ease delivery & Very effective \\
\hline Wild mango (Irvingia gabonensis) & $15(10 \%)$ & Manage constipation & Very effective \\
\hline Vernonia conferta Benth. Barks & $9(3.4 \%)$ & Relieve chronic pelvic pains & Unknown \\
\hline Unknown herbs & $18(12.3 \%)$ & Unknown & \\
\hline
\end{tabular}

\section{General characteristics of the study population}

The ages of the parturients ranged from 15-45 years with an average of $28.88 \pm 6.31$ years in the exposed group and $27.90 \pm 6.30$ years in the non-exposed group. The most represented age group was 25-34 years old. Table 2 shows the distribution of the population by age. With regards to marital status, $48.3 \%$ were singled and $36.5 \%$ married. Women living in liberal unions were about twice as likely to ingest CAM during labour ( $R R=1.79,95 \%$ CI $1.10-2.94, \mathrm{p}=0.016$ ) compared to their counter parts. Having at a secondary level of education conveyed protection against the use of CAM during labour $(\mathrm{RR}=0.68,95 \% \mathrm{CI} 0.47-0.99, \mathrm{p}=0.028)$. In contrast, parturients with a tertiary level of education were 1.5 times more likely to use CAM (RR $=1.5895 \%$ CI 1.08-2.33, $\mathrm{p}=$ 0.012 ). 


\section{Global Journal of Reproductive Medicine}

Table 2: Distribution of the list of Complementary and Alternative Medicine used in terms of percentage use; reason for using and subjective perception.

\begin{tabular}{|c|c|c|c|c|c|}
\hline Variables & Total N=603 (\%) & Exposed group $\mathrm{N}=147(\%)$ & Non-exposed group $\mathrm{N}=456(\%)$ & Risk ratio $(95 \% \mathrm{CI})$ & P value \\
\hline \multicolumn{6}{|c|}{ Age (years) } \\
\hline $15-25$ & $181(30)$ & $38(25.9)$ & $143(31.4)$ & $0.76(0.50-1.16)$ & 0.122 \\
\hline $26-35$ & $181(30)$ & $79(56.5)$ & $238(57.2)$ & $1.06(0.73-1.54)$ & 0.407 \\
\hline $36-45$ & $105(17.3)$ & $30(20.6)$ & $75(16.4)$ & $1.30(0.81-2.09)$ & 0.164 \\
\hline \multicolumn{6}{|c|}{ Marital status } \\
\hline Single & $291(48.3)$ & $64(43.5)$ & $227(49.8)$ & $0.78(0.53-1.13)$ & 0.111 \\
\hline Married & $220(36.5)$ & $52(35.4)$ & $168(36.8)$ & $0.94(0.63-1.38)$ & 0.413 \\
\hline Divorced & $7(1.2)$ & $2(1.4)$ & $5(1.1)$ & $1.24(0.24-6.48)$ & 0.54 \\
\hline Widow & $19(0.2)$ & $0(0)$ & $1(0.2)$ & 0 & 0.756 \\
\hline Liberal unions & $84(13.8)$ & $29(19.7)$ & $55(12.1)$ & $1.79(1.10-2.94)$ & 0.016 \\
\hline \multicolumn{6}{|c|}{ Level of education } \\
\hline No formal education & $30(5)$ & $9(6.1)$ & $21(4.6)$ & $1.35(0.60-0.29)$ & 0.294 \\
\hline Primary & $94(15.6)$ & $20(13.6)$ & $74(16.2)$ & $0.81(0.48-1.39)$ & 0.267 \\
\hline Secondary & 277 (45.9) & $57(38.8)$ & $220(48.2)$ & $0.68(0.47-0.99)$ & 0.028 \\
\hline Tertiary & $202(33.5)$ & $61(41.5)$ & $141(30.9)$ & $1.58(1.08-2.33)$ & 0.012 \\
\hline
\end{tabular}

The influence of traditional medicine on labor and labour $(R R=1.45,95 \% C I=1.10-1.91, p=0.007)$. Furthermore, delivery

The most common reason for admission was labour pains in $57.4 \%$. CAM almost doubled the risk of intra-partum vaginal bleeding $(\mathrm{RR}=1.51,95 \% \mathrm{CI}=1.10-2.08, \mathrm{p}=0.011)$ and dystocic parturients who used TM during labour had a 1.27-fold increase in the risk of uterine hyper kinesia $(\mathrm{RR}=1.27,95 \% \mathrm{CI}=1.06-1.52$, $\mathrm{p}=0.008)$ and 7 -fold increase in uterine atony ( $\mathrm{RR}=7.24,95 \%$ $\mathrm{CI}=1.90-27.63, \mathrm{p}=0.002$ ). There was no significant association between neonatal complications and TM intake as seen in Table 3.

Table 3: Logistic regression analysis of the influence of Complementary and Alternative Medicine on labour and delivery.

\begin{tabular}{|c|c|c|c|c|c|}
\hline Variables & Total N=603 (\%) & Exposed group N=147(\%) & $\begin{array}{c}\text { Non-exposed group } \\
\text { N=456(\%) }\end{array}$ & Risk ratio (95\% CI) & P value \\
\hline \multicolumn{5}{|c|}{ Presenting complaints } \\
\hline Lost of liquoir & $88(14.6)$ & $15(10.2)$ & $73(16)$ & $0.66(0.41-1.08)$ & 0.051 \\
\hline Vaginal bleeding & $100(16.6)$ & $34(23.1)$ & $66(14.5)$ & $1.51(1.10-2.08)$ & 0.011 \\
\hline Labour pains & $346(57.4)$ & $90(61.2)$ & $74(14.7)$ & $0.90(0.59-1.37)$ & 0.367 \\
\hline $\begin{array}{c}\text { APGAR score at } 1^{\text {st }} \\
\text { minute }<7\end{array}$ & $94(14.4)$ & $20(13.4)$ & $58(11.6)$ & $0.77(0.46-1.28)$ & 0.187 \\
\hline $\begin{array}{c}\text { APGAR score at } 5^{\text {th }} \\
\text { minute }<7\end{array}$ & $71(10.9)$ & $13(8.6)$ & $109(23.9)$ & $1.45(1.10-1.91)$ & 0.007 \\
\hline Dystocic labour & $160(26.5)$ & $51(34)$ & $198(43.4)$ & $1.27(1.06-1.52)$ & 0.008 \\
\hline uterine hyperkinasia & $279(46.3)$ & $71(55.1)$ & $3(0.7)$ & $7.24(1.90-27.63)$ & 0.002 \\
\hline Uterine atony & $10(1.7)$ & $7(4.8)$ & $0.161)$ \\
\hline
\end{tabular}

\section{Discussion}

This study aimed to determine the effects of oral CAM intake during labour on the maternal and foetal outcomes. We found that parturients who ingested CAM during labour had a greater risk of vaginal bleeding prior to admission, uterine hyper kinesia, dystocic delivery and uterineatony. TM use during labour had no effect on foetal outcome.

\section{Incidence of CAM use during labour and general characteristics of the study population}

The incidence of CAM use in thisstudywas $24.4 \%$. This incidence is lower than that of Holst et al in Sweden [6], and Mabina et. al in South Africa [7], who observed incidence rates of CAM use of $36 \%$ and $55 \%$, respectively. This disparity could be explained by the fact that, their incidences entail the use of CAM during pregnancy and labour, compared to our study which focused on intra partum CAM use. About eight different CAM were reported to being tested by parturients in our cohort, of which the most common were honey (28.2\%), Triumfettapentandra A. (23.7\%), followed by the Hibiscus rosa-sinensis L. (20\%). Several parturients reported to use more than one CAM during labour. The maximum association observed was three CAM per parturients. This result is similar to that of Nordeng et al. [8], who found an average CAM combination of two per women. Congruent with the findings of Awouda et al. [3] and Azriani et al. [5], the main reason for CAM consumption during labour was to ease delivery. 


\section{Global Journal of Reproductive Medicine}

The most represented age group was aged between 25-34 years. This is similar to the report of Hepner et al. in Massachusetts [9]; suggesting that the 25-34 years age group might be a potential target group to implement preventive strategies for CAM use during pregnancy and labour. Parturients in liberal unions almost had a double risk of taking CAM. This result follows the trend of the general population, as cohabitation is very common in Cameroon. Secondary education was found to convey protection against CAM use while tertiary education increased the odds of CAM in take during labour. These results concur with those of several authors $[2,6,8,10,11]$. This can be explained by the fact that women with a lower level of education are more likely to rely on the recommendations of their health care providers whom are often against taking CAM during gestation.

\section{The influence of traditional medicine on labor and delivery}

Amongst the complications of CAM ingestion during labor, we observed a significant risk of uterine hyper kinesia ( $p=0.008)$. Although we did not precisely identify which CAM had this effect, this may infer that CAM has a uterotonic property. As for honey, previous studies revealed that this CAM contains oestrogen, which could explain the uterotonic action. Furthermore, honey is rich in carbohydrates, proteins, lipids, organic acids, enzymes, mineral salts and natural antibiotic factors grouped under the term inhibin, which all act in synergy to procure stronger uterine contractions [8]. However, honey also has some toxicity related to the presence of toxic alkaloids or andrometoxin, a toxin from the nectar of the colchicine plant [8]. As such, this increases the risk of uterine atonyin the exposed group.

Another possible explanation is that the hyper kineticuterus becomes fatigued after sometime of intense contraction and eventually failing to contract, leading to uterine atony. Lastly, we did not observe any difference in adverse fetal outcomes between the exposed and un exposed groups. Concurring findings were made by Holst et al. [6], who observed correlation between CAM use and neonatal complications. The findings from the current study should be interpreted with in the context of its limitations. These include the in ability of some parturients to precisely recall what type of CAM was taken during labour. Also, as the study population was drawn from only two referral maternities of Cameroon, preventing the generalizability of the finding she rein.

However, based on a large sample $(n=603)$ of well followed-up parturients, we have used a cohort design to provide a contribution of level II scientific evidence on the current scarcity of data on the maternal and fetal outcomes of intrapartum CAM use in the tropics. These findings should serve as a preliminary reference to refute CAM use during labour in our resource constrained environments.

\section{Conclusion}

Over all, we found that about one parturient out of every four uses CAM during labour. Some socio-demo graphic characteristics such as liberal union and tertiary level of education predispose pregnant women to CAM ingestion during labour. Oral CAM in take increased the risk of vaginal bleeding prior to consultation, uterine hyper kinesia, dystocic delivery and uterineatony.

\section{Conflicts of interest}

The authors declare that they have no conflicts of interest.

\section{Acknowledgments}

The authors thank all the staff of the Maternity units of the Yaounde Central Hospital and the Yaounde of the GynecoObstetrics and Pediatric Hospital of Yaoundé for partaking in the care of all the participants included in this study. We also acknowledge the study participants for their commitment.

\section{References}

1. World Health Organization (2013) Factsheet 134: traditional medicine, Geneva.

2. Steel A, Adams J, Sibbritt D, Broom A, Gallois C, et al. (2012) Utilisation of complementary and alternative medicine (CAM) practitioners within maternity care provision: results from a nationally representative cohort study of 1,835 pregnant women.BMC Pregnancy and Childbirth 12(1): 146.

3. Awouda N (2012) Traditional medicine use in the second half of pregnancy and outcome of labour. Medicine 178p.

4. Andrews G, Adams J, Segrott J (2009) Alternative medicine in the concept of care London. Black well 587-603.

5. Azriani A, Siti A, Zulkifli A, Halim S, Wan N, et al. (2009) Women's attitude and socio- demographic characteristics influencing usage of herbal medicine during pregnancy in Tumpat district, Kelantan. South east Asian J Trop Med Public Health 40(2): 330-337.

6. Holst L, Wright D, Haavik S, Nordeng H (2009) The use and the user of herbal remedies during pregnancy. J Altern Complement Med 15(7): 787-792.

7. Mabina MH, Pitsoe SB, Moodley J (1997) The effect of traditional herbal medicines on pregnancy outcome. The King Edward VIII Hospital experience. S Afr Med J 87(8): 1008-1010.

8. Nordeng $\mathrm{H}$, Hedvig $\mathrm{H}$, Gro C (2005) Impact of socio-demographic factors, knowledge and attitude on the use of herbal drugs in pregnancy. Acta Obstet Gynecol Scand 84(1): 26-33.

9. Hepner DL, Harnett M, Segal S, Camann W, Bader A, et al. (2002) Herbal medicine use in parturients. Anesth Analg 94(3): 690-693.

10. Gibson P, Powrie R, Star J (2001) Herbal and alternative medicine use during pregnancy: A cross sectional survey. Obstet Gynecol 97(4): 4445.

11. Mohammadreza S, Maryam D, Hadi H, Simin OM (2012) Self-reported Use and Attitudes Regarding Herbal Medicine Safety during pregnancy in Iran. Jundishapur J Nat Pharm Prod 7(2): 45-49. 


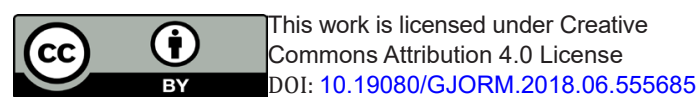

Your next submission with Juniper Publishers will reach you the below assets

- Quality Editorial service

- Swift Peer Review

- Reprints availability

- E-prints Service

- Manuscript Podcast for convenient understanding

- Global attainment for your research

- Manuscript accessibility in different formats

( Pdf, E-pub, Full Text, Audio)

- Unceasing customer service

Track the below URL for one-step submission https://juniperpublishers.com/online-submission.php 